This article was published in Environmental Science and Pollution Research, 23(14), 13877-13885, 2016

http://dx.doi.org/10.1007/s11356-016-6555-y

\title{
Children exposure to indoor ultrafine particles in urban and rural school environments
}

\author{
João Cavaleiro Rufo ${ }^{1,2,3}$ \& Joana Madureira ${ }^{1}$ \& Inês Paciência ${ }^{1,2,3}$ \& Klara Slezakova 4 \\ \& Maria do Carmo Pereira 4 \& Lívia Aguiar 3,5 \& João Paulo Teixeira 3,5 \& André Moreira ${ }^{2}$ \\ $\&$ Eduardo Oliveira Fernandes ${ }^{1}$
}

\author{
${ }^{1}$ INEGI, Rua Dr. Roberto Frias, 4200-465 Porto, Portugal \\ 2 Faculty of Medicine of the University of Porto, Al. Prof. Hernâni Monteiro, 4200-319 Porto, \\ Portugal \\ 3 Epidemiology Research Unit - Institute of Public Health (EPIUnit), University of Porto, Rua \\ das Taipas n 135 , Porto 4050-600, Portugal \\ 4 LEPABE, Faculty of Engineering of University of Porto, Rua Dr. Roberto Frias, 4200-465 \\ Porto, Portugal \\ 5 National Institute of Health, Rua Alexandre Herculano, 321, 4200-055 Porto, Portugal
}

\begin{abstract}
Extended exposure to ultrafine particles (UFPs) may lead to consequences in children due to their increased susceptibility when compared to older individuals. Since children spend in average $8 \mathrm{~h} /$ day in primary schools, assessing the number concentrations of UFPs in these institutions is important in order to evaluate the health risk for children in primary schools caused by indoor air pollution. Thus, the purpose of this study was to assess and determine the sources of indoor UFP number concentrations in urban and rural Portuguese primary schools. Indoor and outdoor ultrafine particle (UFP) number concentrations were measured in six urban schools (US) and two rural schools (RS) located in the north of Portugal, during the heating season. The mean number concentrations of indoor UFPs were significantly higher in urban schools than in rural ones $(10.4 \times$ $10^{3}$ and $5.7 \times 10^{3} \mathrm{pt} / \mathrm{cm}^{3}$, respectively). Higher UFP levels were associated with higher squared meters per student, floor levels closer to the ground, chalk boards, furniture or floor covering materials made of wood and windows with double-glazing. Indoor number concentrations of ultrafine-particles were inversely correlated with indoor $\mathrm{CO} 2$ levels. In the present work, indoor and out- door concentrations ofUFPs in public primary schools located in urban and rural areas were assessed, and the main sources were identified for each environment. The results not only showed that UFP pollution is present in augmented concentrations in US when compared to RS but also revealed some classroom/school characteristics that influence the concentrations of UFPs in primary schools.
\end{abstract}


Keywords Ultrafine particles · Primary schools · Indoor air · Children exposure · Traffic-related UFP $\cdot$ Rural environment

\section{Introduction}

For many years, the exposure to airborne PM2.5 and PM10 has been an important subject of attention for public health (Englert 2004), which led to the creation of guidelines and strategies to reduce the health risk caused by PM2.5 and PM10 (WHO 2005). However, there are no regulations regarding ultrafine particles (UFPs) which are smaller particles (aerodynamic diameter $<0.1 \mu \mathrm{m})$ with a high interfacial area. They are strong sources of oxidative stress and lung inflammation, possibly causing the onset or exacerbation of asthma and other respiratory diseases (Meier et al. 2015). UFPs have been associated with a stronger toxicity when compared to PM2.5 and PM10 due to their proficiency for penetrating cell membranes (Penttinen et al. 2001, Peters et al. 1997, Semmler et al. 2004). Moreover, results from previous studies suggest that long-term exposure to high number concentrations of UFPs may be responsible for an impairment of lung function, development and exacerbation of respiratory diseases such as asthma or chronic obstructive pulmonary disease, and may be even responsible for some carcinogenic activity, among other adverse health effects (Alessandrini et al. 2009, Alessandrini et al. 2006, Andersen et al. 2010, Ferreira et al. 2013, Stanek et al. 2011).

There is currently a knowledge gap concerning the hazardous effects of exposure to UFPs in indoor environments (Sioutas et al. 2005). This is especially true for specific risk groups such as children. The early school years are considered as a long period of vulnerability given that susceptibility to environmental threats is elevated (Fonseca et al. 2014).

Although a portion of indoor UFPs may originate from outdoor sources, from vehicle emissions and gas-to-particle conversions (Kulmala et al. 2004, Levy et al. 2003), the degree of infiltration from outdoor to indoor environments (penetration factor) is very small for UFPs when compared to PM2.5 and PM10 (Long et al. 2001). Thus, outdoor particle number concentrations may not adequately reflect indoor concentrations, particularly in winter, when the ventilation rates are diminished (Weichenthal et al. 2007). Nevertheless, previous studies also showed that the majority of indoor UFPs are originated from indoor sources and that higher particle number concentrations may be associated with longer occupation times and, therefore, it is important to assess UFP number concentrations both from indoor and outdoor sources (Beko et al. 2013, Cavaleiro Rufo et al. 2015, Isaxon et al. 2015, Vinzents et al. 2005, Wallace \& Howard-Reed 2002, Weichenthal et al. 2007). Certain features that may influence outdoor UFP number concentrations such as the different characteristics of urbanization and traffic intensity, industrial activity and densely packed housing are characteristically present in urban environments and rarely seen in rural environments (Kumar et al. 2010, Matson 2005, Yoon et al. 2011). Consequently, it is also important to measure outdoor concentrations when trying to assess indoor exposure. Therefore, it is relevant to study the differences between rural and urban environments when assessing indoor UFP number concentrations.

Schoolchildren spend a significant part of their daytime at school, often under reduced ventilation conditions in winter (Annesi-Maesano et al. 2013), and therefore are largely ex- posed to indoor UFPs. Moreover, children tend to be more susceptible to UFPs toxicity particularly due to their immature respiratory systems and reduced lung function (Schwartz 2004). Although there has 
been some concern regarding the topic, which may be epitomized by several published studies (Buonanno et al. 2013a, Buonanno et al. 2013b, Cavaleiro Rufo et al. 2015, Diapouli et al. 2008, Fromme et al. 2007, Morawska et al. 2009), there are no studies assessing children exposure to UFPs in urban and rural primary schools in Portugal. However, Fonseca et al. (2014) recently published a study concerning pre-school children exposure to UFPs in two urban and one rural pre-schools, where it was not only shown that children in urban pre-schools are more exposed to UFP pollution than children in rural schools, but they are also four to six times more exposed than adults with similar daily schedules. Since primary schoolchildren spend more time in school than pre-schoolchildren, with longer lecture periods, it is possible that the exposure to indoor UFPs is also higher. Thus, it is important to assess the number concentrations of UFPs in Portuguese primary schools in order to evaluate the level of exposure of 5 to 10-year-old children to these particles, as well as identifying their indoor sources, unremittingly considering the differences between urban and rural environments that may differently influence indoor UFP number concentrations.

The purpose of this study was to assess indoor UFP number concentrations in urban and rural Portuguese primary schools and to investigate tendencies of outdoor emission sources and building/classroom characteristics influencing indoor UFPs in naturally ventilated classrooms.

\section{Material and methods}

A walkthrough inspection to collect relevant building/ classroom characteristics, concurrently with the indoor and outdoor sampling of UFPs, was carried out in public primary schools within the framework of ARIA project, between January and February 2014.

\section{Sampling sites}

Primary schools in Portugal are responsible for the education of children after pre-school. Children attendance in primary school is compulsory and, in general, they spend approximately $8 \mathrm{~h}$ per day in these institutions, from Monday to Friday.

In the current study, indoor and outdoor real-time measurements of UFPs were performed in six public primary schools (22 classrooms) located in the urban area of Porto (US1 to US6), Portugal, with approximately 230,000 habitants and two public primary schools ( 2 classrooms) from a rural area in Trofa (RS1 and RS2), Portugal, situated $20 \mathrm{~km}$ north of Porto, with approximately 39,000 habitants. All classrooms were naturally ventilated and were sampled under winter weather conditions (January to February 2014). Further information regarding classroom characteristics, including density of occupation and window characteristics can be found in Table 1 .

The measurements were performed during regular activities and under representative conditions of occupancy and use of the classrooms. Outdoor UFP number concentrations were also measured for 1 weekday in each school in order to evaluate the influence of outdoor sources in indoor UFP number concentrations. Safe and childproof sampling sites were ensured and complied with the rules as prescribed by ISO 16000-1 (2004) (International Standardization Organization 2004).

\section{Walkthrough inspection}

The walkthrough inspection was completed in each school by a trained researcher who gathered information related to school building/classroom characteristics. The recorded information included 
outdoor characterization, building construction characteristics, ventilation and heating systems, past occurrences or visible problems, building usage and potential indoor sources. Classroom characteristics such as the area, floor, walls, and ceiling conditions, windows, scholar activity products (paintings, glues, etc.), maintenance routines and cleaning procedures were also recorded, as well as the type of classroom furniture, the presence of chalkboards, copiers, plants and information about environmental modifiers including air fresheners and insecticides.

\section{Sampling acquisition}

The indoor measurements took place during the teaching hours (from 9:00 to 17:30 h). There were three recess periods occurring from 10:30 to $11: 00 \mathrm{~h}$, from 12:30 to 14:00 $\mathrm{h}$, and from 16:00 to $16: 30 \mathrm{~h}$. The first recess period in US4 takes place between 10:00 and 10:30 $\mathrm{h}$ instead. These were non- occupation periods and thus were not considered as periods of children exposure for the statistical analysis.

Two portable condensation particle counters(P-Trak model 8525, TSI Inc., MN, USA) were used for the assessment of UFP number concentrations. The operation mechanism of these particle counters is based on the principle of condensing $100 \%$ grade isopropyl alcohol (Sigma-Aldrich, Steinheim, Germany) onto UFPs in order to increase their dimensions to detectable sizes (Jenkins et al. 2004). The concentration measurement capacity of the P-Trak range from 0 to $5 \times 10^{5}$ particles $/ \mathrm{cm}^{3}$ and the particle size range from 0.02 to $1 \mu \mathrm{m}$. Instruments were installed inside each classroom and were set to continuously measure during at least one school day $(8 \mathrm{~h}$, avoiding Mondays and Fridays). Logging intervals were set to 1 min between each sample according to previous studies (Fonseca et al. 2014, Norback et al. 2011, Zhang \& Zhu 2012). The second instrument was set to concurrently sample the outdoor environment for the same period of time. The instruments are calibrated annually by the manufacturer. Validation tests were performed to evaluate acquisition differences between the instruments. No statistically significant differences were found. Further detailed characterization of the equipment has been previously reported (Matson et al. 2004). The instruments that were sampling indoors were mounted on a flat surface with a height of 1.2 to $1.5 \mathrm{~m}$ in order to simulate the primary school children breathing zone. Moreover, in each classroom, the particle counters were placed as far as possible from windows or doors as well as from major indoor sources of UFPs (heaters, blackboards, printers, etc.). The sampling process was supervised by a researcher.

The particle counters sampling the outdoor environment were installed in the school's playground, in a safe distance from intense activity zones, such as football fields, and were always positioned in open areas avoiding obstacles that could interfere with the data acquisition (trees, walls, etc.). Similarly to the indoor setup, the instrument was positioned on a flat surface 1.2 to $1.5 \mathrm{~m}$ above ground, protected from rain and from intense dust zones.

Carbon dioxide ( $\mathrm{CO} 2)$ was recorded every 5 min concurrently with the UFP indoor and outdoor sampling using IAQ- CALC monitors (model 7545, TSI Inc., MN, USA). The instruments were calibrated once per year according to manufacturer specifications.

\section{Statistical analysis}

Statistical analysis was performed using SPSS Statistics v20 (IBM). The one-sample KolmogorovSmirnov test was used to check the UFP data distribution normality. Since a non- Gaussian 
distribution was observed, non-parametric tests were used to further analyse the data. MannWhitney and Kruskal-Wallis tests were used to compare continuous variables between two or more categories, respectively. The Spearman's correlation test was used for comparisons between continuous variables. Linear regression analysis was used to find how indoor UFP number concentrations are related to indoor $\mathrm{CO}_{2}$ levels. Statistical significance was considered when $p<$ 0.05 .

\section{Results}

The average values of indoor and outdoor UFP number concentrations measured in each school, as well as the indoor/ outdoor $(\mathrm{I} / \mathrm{O})$ ratios, are displayed in Table 2 .

A significant difference in indoor UFP number concentrations was found between the different school environments $(p<0.01$, Mann-Whitney test), being the concentrations higher among urban schools $\left(10.4 \times 10^{3} \pm 150 \mathrm{pt} / \mathrm{cm}^{3}\right)$ when compared to rural schools $\left(5.7 \times 10^{3} \pm 93 \mathrm{pt} / \mathrm{cm}^{3}\right)$. Moreover, a significant difference between indoor and outdoor UFP number concentrations was found in urban schools, being indoor levels higher than outdoors ( $p<0.01$, Mann-Whitney test). Contrarily, indoor UFP number concentrations in the rural area were significantly lower than outdoors ( $p<0.01$, Mann- Whitney test). The I/O ratios were above the unity in four of the six urban schools (US1, US4, US5 and US6) and in one of the two rural schools (RS1).

The Mann-Whitney test showed significant associations between several building/classroom characteristics and UFP number concentrations (Table 3). Classrooms with occupational density ( $\mathrm{m}^{2}$ per student) over $2.5 \mathrm{~m}^{2}$ showed significantly higher number concentrations of UFP when compared to densities under $2.5 \mathrm{~m}^{2}(p<0.01)$. The Spearman's correlation test also showed significant positive correlations between UFP number concentrations and the occupational density $(p<0.05 ; r h o=0.52)$. Classrooms located on the ground floor also showed significantly higher UFP concentrations when compared to those on the first storey ( $p<0.01$; no classrooms located over the first storey were included in this study). Classrooms with chalk boards presented significantly higher particles than classrooms with white boards for markers $(p<0.01)$, and those with wood-based furniture or floor covering materials showed significantly higher UFP concentrations when compared to those without these characteristics ( $p<0.01$ for both situations). Classrooms with double-glazing windows showed significantly higher UFP number concentrations when compared to those with single-glazing windows $(p<0.01)$. Finally, cooking meals in the schools was significantly associated with higher UFP concentrations $(p<0.01)$. No associations were found between particle number concentrations and having a sink in the classroom or the different types of window frame material $(p>0.05)$.

With regard to $\mathrm{CO}_{2}$ concentrations, the Spearman's test showed that there was a significant negative correlation be- tween indoor UFP number concentrations and $\mathrm{CO} 2$ levels, independently of the type of environment $(p<0.05$, rho $=-0.51)$. Temperature was negatively correlated with relative humidity $(p<0.01$, rho $=-0.65$ ), although there were no significant correlations between these comfort parameters and UFP concentrations. 


\section{Discussion}

In this work, indoor and outdoor UFP number concentrations were measured in eight public primary schools comprising 24 classrooms from urban and rural areas. UFP number concentrations were assessed for a period of $6 \mathrm{~h}$ corresponding to the exposure time that children spend inside the classrooms, per day. Special attention was given to building/classroom characteristics, as well as to the school's surroundings. A study focused on sampling UFPs in pre-schools in urban and rural environments has been previously performed in Portugal (Fonseca et al. 2014). Considering that children move directly from pre-schools to primary schools, these two studies combined show a possible estimation of children's exposure to UFPs during 7 critical years of their childhood ( 3 to 10 years old) in urban and rural areas. This is a major strength of this work since the high dependence of UFPs on proximity to different sources and environments is one of the main reasons behind the difficulty to establish reference and threshold values for UFPs in public buildings, such as schools (Meier et al. 2015). Moreover, this study investigated associations between building/classroom characteristics and UFP number concentrations in different environments, which may have shared some light on the most important indoor sources of UFPs in primary schools. This study may also provide important evidence in a foreign context, namely in countries with similar building construction, sources of particles (outdoor and indoor) and climatic conditions.

The results revealed significantly higher number concentrations of UFPs in urban environments when compared to rural schools, which evidently may be associated with the higher traffic density typical of large cities, corroborating the results from previous studies in other countries (Matson 2005, Yoon et al. 2011). However, the indoor concentrations of UFPs were significantly higher indoors than outdoors in urban schools and the I/O ratios were generally higher than rural schools $(\mathrm{I} / \mathrm{O}=1.16$ vs. $\mathrm{I} / \mathrm{O}=0.97)$, suggesting a smaller contribution of UFPs from outdoor sources. The reason behind the high I/O ratios of UFPs in urban schools may be related with the classrooms' characteristics as previously reported by a study concerning five schools in Texas (Zhang \& Zhu 2012). The results obtained during this study regarding the impact of certain classroom characteristics on UFP concentrations such as the storey number, the windows frame material, or the cooking activities, support this hypothesis.

Larger rooms with more empty space are inclined to have more particles in resuspension resultant from simple physical activities, such as walking (Laiman et al. 2014, Nazaroff 2004). This has been supported by the current study since the classrooms with higher squared meters per child showed higher concentrations of UFPs in a significant correlated proportion.

In addition, classrooms in the ground floor appeared to be more susceptible to outdoor emissions of UFPs since they presented higher concentrations of particles when compared to those on the upper floors, supporting the results obtained by Spilak et al. (2014). This suggests that classrooms located on lower floor levels are more exposed to UFPs originated from outdoor origins than those located on upper levels. Similarly, classrooms with chalk boards tend to have higher concentrations of UFPs than those without chalkboards. Salma et al. (2013) estimated that writing and wiping on a chalk board was the activity that produced larger concentrations of particulate matter in a classroom. Particles released from human activities involving chalk boards tend to be of larger sizes, such as PM10 and PM2.5 (Amato et al. 2014). However, there may be some possible contribution from chalk boards to in- doorUFP concentrations.

Interestingly, wood-based furniture or floor covering materials were associated with increased particle concentrations. This supports the results obtained by the previously mentioned study from 
Spilak et al. (2014), where higher levels of UFPs were also associated with wood-type floors. Although there is large evidence that UFPs originate from wood combustion or wood sanding during furniture production (Torvela et al. 2014, Welling et al. 2008), there is few data concerning the possible production of ultrafine particulate matter from secondary reactions between certain chemical agents and wood. For instance, the act of sweeping the floor with floor cleaning products is known to produce UFPs due to secondary reactions between the chemical agents and ozone (Nazaroff \& Weschler 2004); therefore, it is possible that these chemicals may also react with wood components producing secondary organic aerosols. Further research is needed to investigate these associations.

Increased UFP levels were also associated with classrooms of schools that prepared the children's meals in the building. The act of cooking is documented to produce significant amounts of UFPs due to the combustions involved in the process (Isaxon et al. 2015). Many schools in Portugal have poor exhaustion systems in the kitchen and canteens; thus, it is possible that some of these particles penetrate to the classroom environment contributing to the indoor air concentration of UFPs. However, this result needs to be interpreted with caution since there was only one school that cooked meals inside the building during the present study (US5).

Classrooms with double-glazed windows were associated with higher UFP concentrations when compared to class- rooms with single-glazed windows. Although double- glazing retrofitting is known to impact indoor air quality in several aspects (Shrubsole et al. 2015), there is no evidence that double-glazed windows may contribute to increase the indoor number concentrations of UFPs. The window frame material, on the other hand, showed no influence on UFP concentrations. Unfortunately, none of the studied schools had wood-based window frames, which would be interesting to further study the production of UFPs from wood materials. Nevertheless, these results suggest an interesting perspective concerning window-types that should be studied more intensely in the future.

Indoor concentrations of $\mathrm{CO} 2$ were inversely correlated to UFPs, which is in accordance with those obtained by Cavaleiro Rufo et al. (2015) in a sample of 10 urban schools. Considering that $\mathrm{CO}_{2}$ is a recognized indirect marker of ventilation (ASHRAE2004, Daisey et al. 2003, Mahyuddin et al. 2008), we may speculate that outdoor UFPs may penetrate to indoor environment when the windows are open (lower $\mathrm{CO}_{2}$ concentrations) and, after closing the windows (higher $\mathrm{CO}_{2}$ concentrations), the contribution of UFPs from outdoors to indoors decreases. Nevertheless, more detailed information regarding the ventilation habits during the sampling campaigns needs to be obtained in future work in order to compare daily profiles of indoor UFPs with the number of open and/or closed windows.

The present study, such as many other studies concerning indoor air monitoring during normal occupational activities, has some limitations that should be taken into consideration when interpreting the presented results. First, considering that the P-Trak model used for assessing UFP number concentrations measures particles smaller than $1 \mu \mathrm{m}$ and that UFPs are defined as having a diameter inferior to $0.1 \mu \mathrm{m}$, larger particles may have contributed to the resultant mean concentrations. Nevertheless, Kumar et al. (2011) showed that, unlike mass concentrations, the majority of particle number concentrations consist in particles under $0.1 \mu \mathrm{m}$; thus, the risk of significant bias in the overall number concentrations of UFPs in each classroom associated with the count of larger particles at the moment of the sampling is low. Second, due to logistical limitations, the sample size is somehow disproportioned between rural and urban schools ( 2 vs 6 , respectively). The number of rural schools should also be ex- tended in a future study to better support and understand the magnitude of the differences between schools in different 
environments. Third, reactions between ozone with a complex mixture of volatile organic compounds from human skin oil (surface-sorbed squalene), furnishings surfaces (aldehydes, ketones) and cleaning products (d-limonene or a-pinene) have been highlighted as significant secondary UFP-generating processes (Morawska et al. 2009, Wang \& Waring 2014), which could not be identified in the present study since ozone levels were not measured in classrooms. Finally, it is important to have in mind that several building/classroom characteristics evaluated in this study, such as "the curtains standard materials" or "gas as the power source for the heaters", had slightly disproportioned sample of cases for comparison, which may produce some bias. Moreover, since no adjustments were made, only tendencies for increased or decreased UFP concentrations associated with classroom characteristics can be observed; therefore, no accurate source apportionment could be made.

Real-time information regarding the occupant's behaviour in classrooms and the number of windows usually opened per hour should also be collected for further data regarding ventilation practices. In the present study, the researchers supervising the instruments filled a checklist to collect this information. However, as the measurements occurred during the winter time, the school staff rarely opened the windows all the way and the researchers tend to give a percentage of opening (for instance $50 \%$ when the windows were opened half-way). This was unfortunately inconvenient due to the multiple type of windows ( $100 \%$ open in one school may promote less air exchange than a $50 \%$ opened window in another school) and to the different perception of the opened portion of the window. Due to such amounts of confounding factors, the collected data was not considered for the study and priority was given to $\mathrm{CO} 2$ concentrations, which is still a good indirect marker of ventilation. Nevertheless, a better method for collecting data concerning ventilation practices should be developed in future studies.

\section{Conclusions}

This study is the first to assess indoor and outdoor UFP number concentrations in public primary schools located in areas with different characteristics of urbanization and traffic density in the north of Portugal. However, the most relevant contribution of this work resides in the characterization of UFP sources in both environments.

The outcomes showed that UFP pollution is present in augmented concentrations in urban environments when com- pared to rural settings. Indoor UFP number concentrations were also, in general, higher than outdoor concentrations in urban schools, suggesting that indoor sources significantly contribute to the mean indoor UFP concentrations. However, $\mathrm{CO} 2$ concentrations were found to be inversely correlated with UFP number concentrations, which may suggest that the outdoor environment has a large influence on the indoor UFP concentrations. Several building/classroom characteristics were found to be associated with higher levels of UFPs including the occupational density, floor level, the type of classroom board and furniture or floor covering made of wood.

To improve the statistical power of the study, more rural classrooms should be studied in order to better understand the differences between UFPs in urban and rural environments. However, these may be useful to understand and elaborate preventive and effective strategies to reduce indoor air pollution in primary schools caused by UFPs.

Acknowledgments This study was performed in the framework of the ARIA project which is 
financially supported by Fundação para Ciência e Tecnologia (PTDC/DTP-SPA/1522/2012, FCOMP-01-0124-FEDER-028709) and by the scholarships SFRH/BD/108605/2015 and SFRH/ $\mathrm{BD} / 112269 / 2015$.

\section{References}

Alessandrini F, Schulz H, Takenaka S, Lentner B, Karg E, Behrendt H, Jakob T (2006) Effects of ultrafine carbon particle inhalation on allergic inflammation of the lung. $\mathrm{J}$ Allergy Clin Immunol 117: 824-30

Alessandrini F, Beck-Speier I, Krappmann D, Weichenmeier I, Takenaka S, Karg E, Kloo B, Schulz H, Jakob T, Mempel M, Behrendt H (2009) Role of oxidative stress in ultrafine particleinduced exacer- bation of allergic lung inflammation. Am J Respir Crit Care Med 179:98491

Amato F, Rivas I, Viana M, Moreno T, Bouso L, Reche C, Àlvarez- Pedrerol M, Alastuey A, Sunyer J, Querol X (2014) Sources of indoor and outdoor PM2.5 concentrations in primary schools. Sci Total Environ 490:757-765

Andersen ZJ, Olsen TS, Andersen KK, Loft S, Ketzel M, Raaschou- Nielsen O(2010) Association between short-term exposure to ultra- fine particles and hospital admissions for stroke in Copenhagen, Denmark. Eur Heart J 31(16):2034-40

Annesi-Maesano I, Baiz N, Banerjee S, Rudnai P, Rive S, Group S (2013) Indoor air quality and sources in schools and related health effects. J Toxicol Environ Health B Crit Rev 16:491-550

ASHRAE 2004: Standard 62.1: Ventilation for Acceptable Indoor Air quality. American Society of Heating, Refrigeration, and, Air- Conditioning and Engineers, Atlanta, USA

Beko G, Weschler CJ, Wierzbicka A, Karottki DG, Toftum J, Loft S, Clausen G (2013) Ultrafine particles: exposure and source apportionment in 56 Danish homes. Environ Sci Technol 47:10240- 10248

Buonanno G, Fuoco FC, Morawska L, Stabile L (2013a) Airborne particle concentrations at schools measured at different spatial scales. Atmos Environ 67:38-45

Buonanno G, Stabile L, Morawska L, Russi A (2013b) Children exposure assessment to ultrafine particles and black carbon: the role of trans- port and cooking activities. Atmos Environ 79:5358

Cavaleiro Rufo J, Madureira J, Paciência I, Slezakova K, Pereira MC, Pereira C, Teixeira JP, Pinto M, Moreira A, Oliveira Fernandes E (2015) Exposure of children to ultrafine particles in primary schools in Portugal. J Toxicol Env Health Part A 78(13-14):904-14

Daisey JM, Angell WJ, Apte MG (2003) Indoor air quality, ventilation and health symptoms in schools: an analysis of existing information. Indoor Air 13:53-64

Diapouli E, Chaloulakou A, Mihalopoulos N, Spyrellis N (2008) Indoor and outdoor PM mass and number concentrations at schools in the Athens area. Environ Monit Assess 136:13-20

Englert N (2004) Fine particles and human health - a review of epidemiological studies. Toxicol Lett 149:235-42

Ferreira AJ, Cemlyn-Jones J, Robalo Cordeiro C (2013) Nanoparticles, nanotechnology and pulmonary nanotoxicology. Rev Port Pneumol 19:28-37

Fonseca J, Slezakova K, Morais S, Pereira MC (2014) Assessment of ultrafine particles in Portuguese preschools: levels and exposure doses. Indoor Air 24(6):618-28 
Fromme H, Twardella D, Dietrich S, Heitmann D, Schierl R, Liebl B, Rüden H(2007) Particulate matter in the indoor air of classrooms - exploratory results from Munich and surrounding area. Atmos Environ 41:854-866

International Standardization Organization(2004) 16000-1: Indoor air- part 1: general aspects of sampling strategy

Isaxon C, Gudmundsson A, Nordin EZ, Lonnblad L, Dahl A, Wieslander G, Bohgard M, Wierzbicka A (2015) Contribution of indoor- generated particles to residential exposure. Atmos Environ 106: 458-466

Jenkins RA, Ilgner RH, Tomkins BA, Peters DW (2004) Development and application of protocols for the determination of response of real-time particle monitors to common indoor aerosols. J Air Waste Manage Assoc 54:229-241

Kulmala M, Vehkamäki H, Petäjä T, Dal Maso M, Lauri A, Kerminen VM, Birmili W, McMurry PH (2004) Formation and growth rates of ultrafine atmospheric particles: a review of observations. J Aerosol Sci 35:143-176

Kumar P, Robins A, Vardoulakis S, Britter R (2010) A review of the characteristics of nanoparticles in the urban atmosphere and the prospects for developing regulatory controls. Atmos Environ 44: 5035-5052

Kumar P, Robins A, Vardoulakis S, Quincey P (2011) Technical challenges in tackling regulatory concerns for urban atmospheric nano- particles. Particuology 9:566-571

Laiman R, He C, Mazaheri M, Clifford S, Salimi F, Crilley LR, Megat Mokhtar MA, Morawska L (2014) Characteristics of ultrafine particle sources and deposition rates in primary school classrooms. Atmos Environ 94:28-35

Levy JI, Bennett DH, Melly SJ, Spengler JD (2003) Influence of traffic patterns on particulate matter and polycyclic aromatic hydrocarbon concentrations in Roxbury, Massachusetts. J Expo Anal Environ Epidemiol 13:364-71

Long CM, Suh HH, Catalano PJ, Koutrakis P (2001) Using time- and size-resolved particulate data to quantify indoor penetration and de- position behavior. Environ Sci Technol 35:2089-99

Mahyuddin N, Awbi H, Alshitawi M (2008): Investigating carbon dioxide in high occupancy buildings with particular application to class- rooms. Indoor Air, 17-22

Matson U, Ekberg LE, Afshari A (2004) Measurement of ultrafine particles: a comparison of two handheld condensation particle counters. Aerosol Sci Technol 38:487-495

Matson U (2005) Indoor and outdoor concentrations of ultrafine particles in some Scandinavian rural and urban areas. Sci Total Environ 343: 169-76

Meier R, Eeftens M, Aguilera I, Phuleria HC, Ineichen A, Davey M, Ragettli MS, Fierz M, Schindler C, Probst-Hensch N, Tsai MY, Künzli N (2015) Ambient ultrafine particle levels at residential and reference sites in urban and rural Switzerland. Environ Sci Technol 49:27092715

Morawska L, He C, Johnson G, Guo H, Uhde E, Ayoko G (2009) Ultrafine particles in indoor air of a school: possible role of secondary organic aerosols. Environ Sci Technol 43:9103-9109

Nazaroff WW (2004) Indoor particle dynamics. Indoor Air, Supplement 14:175-183

Nazaroff WW, Weschler CJ (2004) Cleaning products and air fresheners: exposure to primary and secondary air pollutants. Atmos Environ 38:2841-2865

Norback D, Wieslander G, Zhang X, Zhao Z (2011) Respiratory symptoms, perceived air quality and physiological signs in elementary school pupils in relation to displacement and mixing ventilation system: an intervention study. Indoor Air 21:427-37 
Penttinen P, Timonen KL, Tiittanen P, Mirme A, Ruuskanen J, Pekkanen J (2001) Number concentration and size of particles in urban air: effects on spirometric lung function in adult asthmatic subjects. Environ Health Perspect 109:319-23

Peters A, Wichmann HE, Tuch T, Heinrich J, Heyder J (1997) Respiratory effects are associated with the number of ultrafine particles. Am J Respir Crit Care Med 155:1376-83

Salma I, Dosztály K, Borsós T, Söveges B, Weidinger T, Kristóf G, Péter N, Kertész Z (2013) Physical properties, chemical composition, sources, spatial distribution and sinks of indoor aerosol particles in a university lecture hall. Atmos Environ 64:219-228

Schwartz J (2004) Air pollution and children's health. Pediatrics 113: 1037-43

Semmler M, Seitz J, Erbe F, Mayer P, Heyder J, Oberdorster G, Kreyling WG (2004) Long-term clearance kinetics of inhaled ultrafine insoluble iridium particles from the rat lung, including transient translocation into secondary organs. Inhal Toxicol 16:453-9

Shrubsole C, Taylor J, Das P, Hamilton IG, Oikonomou E, Davies M (2015) Impacts of energy efficiency retrofitting measures on indoor PM2.5 concentrations across different income groups in England: a modelling study. Advances in Building Energy Research., pp 1-15

Sioutas C, Delfino RJ, Singh M (2005) Exposure assessment for atmoultrafine particles (UFPs) and implications in epidemiologic research. Environ Health Perspect 113:947-55

Spilak MP, Frederiksen M, Kolarik B, Gunnarsen L (2014) Exposure to ultrafine particles in relation to indoor events and dwelling charac- teristics. Build Environ 74:65-74

Stanek L, Sacks D, Dutton J, Dubois B (2011) Attributing health effects to apportioned components and sources of particulate matter: An evaluation of collectiveresults. Atmos Environ45:56555663

Torvela T, Tissari J, Sippula O, Kaivosoja T, Leskinen J, Virén A, Lähde A, Jokiniemi J (2014) Effect of wood combustion conditions on the morphology of freshly emitted fine particles. Atmos Environ 87:65- 76

Vinzents PS, Moller P, Sorensen M, Knudsen LE, Hertel O, Jensen FP, Schibye B, Loft S (2005) Personal exposure to ultrafine particles and oxidative DNA damage. Environ Health Perspect 113:1485-90

Wallace L, Howard-Reed C (2002) Continuous monitoring of ultrafine, fine, and coarse particles in a residence for 18 months in 1999-2000. J Air Waste Manag Assoc 52:828-44

Wang C, Waring MS (2014) Secondary organic aerosol formation initiated from reactions between ozone and surface-sorbed squalene. Atmos Environ 84:222-229

Weichenthal S, Dufresne A, Infante-Rivard C (2007) Indoor ultrafine particles and childhood asthma: exploring a potential public health concern. Indoor Air 17:81-91

Welling I, Lehtimäki M, Rautio S, Lähde T, Enbom S, Hynynen P, Hämeri K (2008) Wood dust particle and mass concentrations and filtration efficiency in sanding of wood materials. $\mathrm{J}$ Occup Environ Hyg 6:90-98

WHO (2005) WHO air quality guidelines for particulate matter, ozone, nitrogen dioxide and sulfur dioxide

Yoon C, Lee K, Park D (2011) Indoor air quality differences between urban and rural preschools in Korea. Environ Sci Pollut Res Int 18: 333-45

Zhang Q, Zhu Y (2012) Characterizing ultrafine particles and other air pollutants at five schools in South Texas. Indoor Air 22:33-42 
Table 1

School building and classroom characteristics

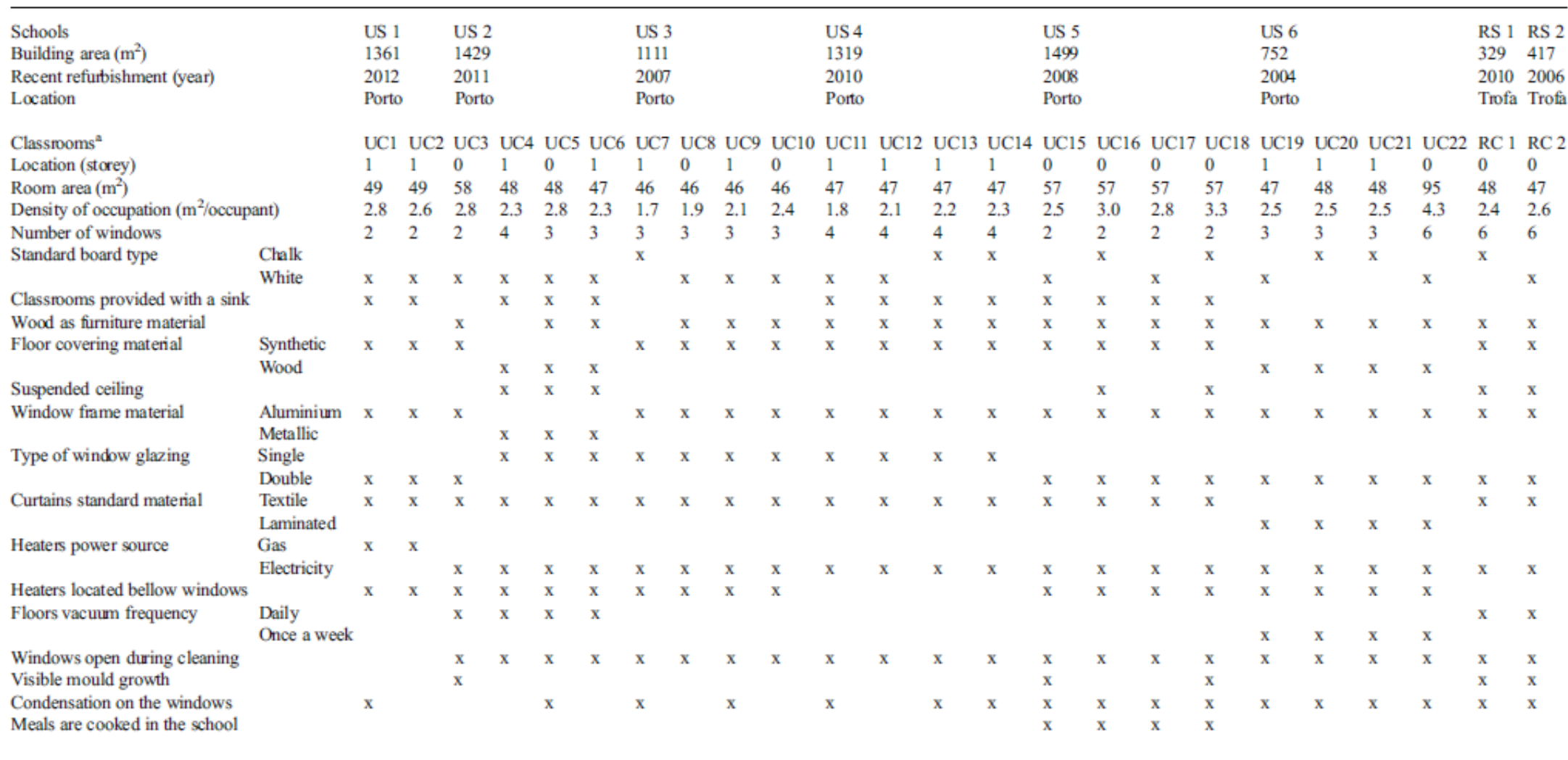

${ }^{\mathrm{a}}$ All classrooms had natural ventilation strategies

US urban school, $U C$ urban classroom, $R S$ rural school, $R C$ rural classoom 
Table 2 - Mean, 50, 25 and 75 percentiles of UFP number concentrations measured in each school, sorted by urban and rural environment.

\begin{tabular}{|c|c|c|c|c|c|c|c|c|c|}
\hline \multirow[t]{3}{*}{ Schools } & \multicolumn{8}{|c|}{ UFP number concentrations $\left(\times 10^{3} \mathrm{pt} / \mathrm{cm}^{3}\right)$} & \multirow{3}{*}{$\mathrm{I} / \mathrm{O}$} \\
\hline & \multicolumn{4}{|l|}{ Indoor } & \multirow[b]{2}{*}{ Mean } & \multicolumn{3}{|l|}{ Outdoor } & \\
\hline & Mean & Median & $\begin{array}{l}25 \text { th } \\
\text { percentile }\end{array}$ & $\begin{array}{l}\text { 75th } \\
\text { percentile }\end{array}$ & & Median & $\begin{array}{l}25 \text { th } \\
\text { percentile }\end{array}$ & $\begin{array}{l}75 \text { th } \\
\text { percentile }\end{array}$ & \\
\hline US 1 & 4.7 & 4.1 & 2.8 & 7.3 & 2.2 & 1.8 & 1.4 & 2.4 & 2.2 \\
\hline US 2 & 7.1 & 6.6 & 5.5 & 8.0 & 8.0 & 7.2 & 5.9 & 9.5 & 0.9 \\
\hline US 3 & 7.4 & 6.4 & 4.6 & 8.0 & 1.9 & 15.4 & 7.8 & 24.6 & 0.4 \\
\hline US 4 & 7.4 & 6.5 & 4.3 & 9.0 & 3.3 & 2.6 & 2.0 & 3.8 & 2.3 \\
\hline US 5 & 17.1 & 10.4 & 6.5 & 18.7 & 8.8 & 7.3 & 5.6 & 10.7 & 1.9 \\
\hline US 6 & 16.1 & 8.2 & 6.0 & 17.1 & 10.2 & 9.3 & 7.9 & 12.1 & 1.6 \\
\hline RS 1 & 7.8 & 7.3 & 5.4 & 10.5 & 5.6 & 3.7 & 3.0 & 5.5 & 1.4 \\
\hline RS 2 & 4.0 & 3.9 & 3.5 & 4.4 & 6.1 & 4.6 & 3.0 & 7.4 & 0.7 \\
\hline
\end{tabular}

US urban school, $R S$ rural school, $I / O$ indoor/outdoor ratios 
Table 3 Classroom characteristics and their impact in indoor UFP mean number concentrations

\begin{tabular}{|c|c|c|c|c|}
\hline \multicolumn{2}{|l|}{ Building/classroom characteristics } & \multirow{2}{*}{$\begin{array}{l}\begin{array}{l}\text { Number of } \\
\text { classrooms }\end{array} \\
15 \\
9\end{array}$} & \multirow{2}{*}{$\begin{array}{l}\begin{array}{l}\text { Mean UFP } \\
\left(\mathrm{pt}^{\left.-\mathrm{cm}^{3}\right)}\right.\end{array} \\
9.0 \times 10^{3} \\
11.5 \times 10^{3}\end{array}$} & \multirow{2}{*}{$\begin{array}{l}p \\
<0.01\end{array}$} \\
\hline Density of occupation ( $\mathrm{m}^{2} /$ occupant) & $\begin{array}{l}>2.5 \\
>2.5\end{array}$ & & & \\
\hline Classroom location & $\begin{array}{l}\text { Ground floor } \\
\text { First storey }\end{array}$ & $\begin{array}{l}11 \\
13\end{array}$ & $\begin{array}{l}11.8 \times 10^{3} \\
8.6 \times 10^{3}\end{array}$ & $<0.01$ \\
\hline Standard board type & $\begin{array}{l}\text { White board } \\
\text { Chalk board }\end{array}$ & $\begin{array}{l}16 \\
8\end{array}$ & $\begin{array}{l}8.7 \times 10^{3} \\
13.1 \times 10^{3}\end{array}$ & $<0.01$ \\
\hline Classroom provided with a sink? & $\begin{array}{l}\text { No } \\
\text { Yes }\end{array}$ & $\begin{array}{l}11 \\
13\end{array}$ & $\begin{array}{l}10.4 \times 10^{3} \\
9.9 \times 10^{3}\end{array}$ & 0.06 \\
\hline Wood as furniture material? & $\begin{array}{l}\text { No } \\
\text { Yes }\end{array}$ & $\begin{array}{l}4 \\
20\end{array}$ & $\begin{array}{l}5.4 \times 10^{3} \\
11.2 \times 10^{3}\end{array}$ & $<0.01$ \\
\hline Floor covering material & $\begin{array}{l}\text { Synthetic } \\
\text { Wood }\end{array}$ & $\begin{array}{l}17 \\
7\end{array}$ & $\begin{array}{l}9.5 \times 10^{3} \\
12.5 \times 10^{3}\end{array}$ & $<0.01$ \\
\hline Window frame material & $\begin{array}{l}\text { Aluminium } \\
\text { Metal }\end{array}$ & $\begin{array}{l}21 \\
3\end{array}$ & $\begin{array}{l}10.4 \times 10^{3} \\
7.1 \times 10^{3}\end{array}$ & 0.07 \\
\hline Type of window glazing & $\begin{array}{l}\text { Single } \\
\text { Double }\end{array}$ & $\begin{array}{l}11 \\
13\end{array}$ & $\begin{array}{l}7.3 \times 10^{3} \\
12.1 \times 10^{3}\end{array}$ & $<0.01$ \\
\hline Meals are cooked in the school & $\begin{array}{l}\text { No } \\
\text { Yes }\end{array}$ & $\begin{array}{l}20 \\
4\end{array}$ & $\begin{array}{l}8.5 \times 10^{3} \\
17.1 \times 10^{3}\end{array}$ & $<0.01$ \\
\hline
\end{tabular}

